\title{
Editorial
}

Technology/Devise

Diabetes Metab J 2020;44:54-55

https://doi.org/10.4093/dmj.2020.0019

pISSN 2233-6079 · eISSN 2233-6087

DIABET\&S \& METABOLISM JOURNAL

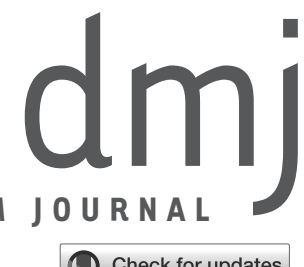

\section{The Potential Role of MicroRNA in Diabetic Cardiomyopathy}

\author{
Jin Hwa Kim \\ Department of Endocrinology and Metabolism, Chosun University Hospital, Chosun University College of Medicine, Gwangju, Korea
}

Diabetic cardiomyopathy (DCM) is a chronic and irreversible diabetic complication, which is manifested as abnormal cardiac structure and function, that is independent of coronary artery disease, valvular disease, and cardiovascular risk factors such as hypertension and dyslipidemia [1,2]. It is characterized by ventricular dilation and hypertrophy, diastolic dysfunction, later by systolic dysfunction, and consequently lead to heart failure [3]. Minimal criteria for diagnosis of DCM include left ventricular diastolic dysfunction and/or reduced left ventricular ejection fraction, left ventricular hypertrophy and interstitial fibrosis [4]. Increased incidence of diabetes can result in an increased prevalence of DCM, which is a major cause of morbidity and mortality in people with diabetes $[5,6]$.

Understanding and identifying the pathogenesis and the underlying mechanism may allow for earlier precision interventions that would lead to improved survival rates and prevention of DCM. Furthermore, identifying the underlying molecular mechanisms of DCM would be valuable for targeted therapy and provide an opportunity to reduce DCM and improve overall public health. Previous studies suggested that cardiac metabolic disturbances such as insulin resistance and glucotoxicity, mitochondrial dysfunction, subcellular signaling disturbance, impaired autophagy, autonomic dysfunction, activation of renin-angiotensin-aldosterone system, inflammation, dysregulation of exosomes, oxidative stress, and immune maladaptation are potential pathophysiological factors $[1,4,6,7]$. However, the pathogenesis of DCM is complex, which may involve various factors such as cardiac hypertrophy, myocardial fibrosis, car- diomyocyte apoptosis, and myocardial metabolic disorders, and the precise molecular and metabolic pathways underlying cardiac dysfunction remains to be understood.

This article entitled "Role of microRNA-34a in anti-apoptotic effects of granulocyte-colony stimulating factor in diabetic cardiomyopathy," along with that published by Park et al. [8], evaluated the mechanism underlying the anti-apoptotic effects of granulocyte-colony stimulating factor (G-CSF) via regulation of microRNA (miRNA)-34a in a DCM rat model. In this study, G-CSF reduced apoptosis of myocardium and induced down-regulation of miR-34a expression. Moreover, transfection with miRNA-34a mimic significantly induced apoptosis in $\mathrm{H} 9 \mathrm{c} 2$ cells. The authors suggested that the anti-apoptotic effects of G-CSF in a rat model of DCM are mediated by reduced expression of miRNA-34a. This approach is quite valuable in establishing a potential therapeutic biomarker for cardiac remodeling in DCM. The authors have clearly shown their results in this manuscript.

Recently, miRNA, which are a class of endogenous, noncoding RNAs with regulatory functions, have been identified as a key element involved in cardiac gene remodeling through post-transcriptional regulation of target gene proteins and suggested a potential diagnostic, prognostic and therapeutic role in diabetes $[9,10]$. A previous study showed that, in cardiac remodeling and the development of heart failure, the synthesis of miRNA and levels of specific miRNA were altered [11]. miRNAs (miR-34b, miR-34c, miR-199b, miR-210, miR-223, and miR-650) might be involved in the pathogenesis of failing
Corresponding author: Jin Hwa Kim (iD https://orcid.org/0000-0003-2703-7033 Department of Endocrinology and Metabolism, Chosun University Hospital, Chosun University College of Medicine, 365 Pilmun-daero, Dong-gu, Gwangju 61453, Korea E-mail: endocrine@chosun.ac.kr
This is an Open Access article distributed under the terms of the Creative Commons Attribution Non-Commercial License (https://creativecommons.org/licenses/by-nc/4.0/) which permits unrestricted non-commercial use, distribution, and reproduction in any medium, provided the original work is properly cited. 
myocardium in patients with diabetes [12]. miRNAs may be involved in cardiac hypertrophy, remodeling and heart failure progression through various process such as mitochondrial function, apoptosis, fibrosis, pyroptosis, and neurohormone secretion [11].

The current study provides a potential new therapeutic approach based on miRNAs and closer precision medicine in diabetic cardiac pathology. Further investigation to determine the potential contribution of various miRNAs to cardiomyopathy in diabetes are needed.

\section{CONFLICTS OF INTEREST}

No potential conflict of interest relevant to this article was reported.

\section{REFERENCES}

1. Jia G, Whaley-Connell A, Sowers JR. Diabetic cardiomyopathy: a hyperglycaemia- and insulin-resistance-induced heart disease. Diabetologia 2018;61:21-8.

2. Jia G1, Hill MA, Sowers JR. Diabetic cardiomyopathy: an update of mechanisms contributing to this clinical entity. Circ Res 2018;122:624-38.

3. Brahma MK, Pepin ME, Wende AR. My sweetheart is broken: role of glucose in diabetic cardiomyopathy. Diabetes Metab J 2017;41:1-9.

4. Isfort M, Stevens SC, Schaffer S, Jong CJ, Wold LE. Metabolic dysfunction in diabetic cardiomyopathy. Heart Fail Rev 2014; 19:35-48.
5. Kim BY, Won JC, Lee JH, Kim HS, Park JH, Ha KH, Won KC, Kim DJ, Park KS. Diabetes fact sheets in Korea, 2018: an appraisal of current status. Diabetes Metab J 2019;43:487-94.

6. Jia G, DeMarco VG, Sowers JR. Insulin resistance and hyperinsulinaemia in diabetic cardiomyopathy. Nat Rev Endocrinol 2016;12:144-53.

7. Falcao-Pires I, Leite-Moreira AF. Diabetic cardiomyopathy: understanding the molecular and cellular basis to progress in diagnosis and treatment. Heart Fail Rev 2012;17:325-44.

8. Park IH, Song YS, Joo HW, Shen GY, Seong JH, Shin NK, Cho YJ, Lee Y, Shin JH, Lim YH, Kim H, Kim KS. Role of microRNA-34a in anti-apoptotic effects of granulocyte-colony stimulating factor in diabetic cardiomyopathy. Diabetes Metab J 2020;44:173-85.

9. Ghosh N, Katare R. Molecular mechanism of diabetic cardiomyopathy and modulation of microRNA function by synthetic oligonucleotides. Cardiovasc Diabetol 2018;17:43.

10. Cirilli I, Silvestri S, Marcheggiani F, Olivieri F, Galeazzi R, Antonicelli R, Recchioni R, Marcheselli F, Bacchetti T, Tiano L, Orlando P. Three months monitored metabolic fitness modulates cardiovascular risk factors in diabetic patients. Diabetes Metab J 2019;43:893-7.

11. Guo R, Nair S. Role of microRNA in diabetic cardiomyopathy: from mechanism to intervention. Biochim Biophys Acta Mol Basis Dis 2017;1863:2070-7.

12. Greco S, Fasanaro P, Castelvecchio S, D’Alessandra Y, Arcelli D, Di Donato M, Malavazos A, Capogrossi MC, Menicanti L, Martelli F. MicroRNA dysregulation in diabetic ischemic heart failure patients. Diabetes 2012;61:1633-41. 